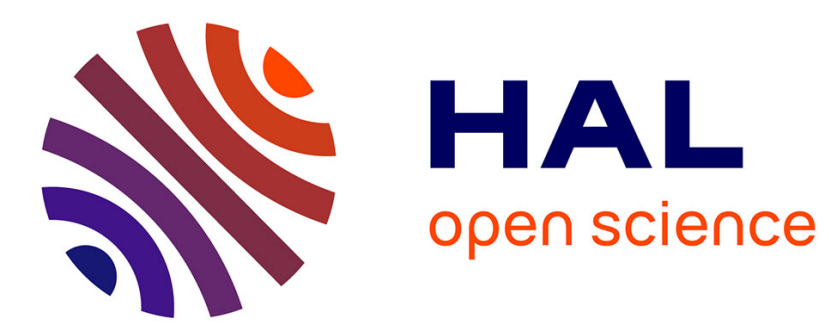

\title{
Le sanctuaire protohistorique de la Fontaine à Nîmes, à la lumière des découvertes récentes
}

Laurent Sauvage

\section{To cite this version:}

Laurent Sauvage. Le sanctuaire protohistorique de la Fontaine à Nîmes, à la lumière des découvertes récentes. Bulletin de l'Association française pour l'étude de l'âge du fer, 1993, 11, pp.56. hal-02867348

\section{HAL Id: hal-02867348 \\ https://hal.science/hal-02867348}

Submitted on 22 Aug 2020

HAL is a multi-disciplinary open access archive for the deposit and dissemination of scientific research documents, whether they are published or not. The documents may come from teaching and research institutions in France or abroad, or from public or private research centers.
L'archive ouverte pluridisciplinaire HAL, est destinée au dépôt et à la diffusion de documents scientifiques de niveau recherche, publiés ou non, émanant des établissements d'enseignement et de recherche français ou étrangers, des laboratoires publics ou privés.

\section{(ㅇ)(1) $\$$}

Distributed under a Creative Commons Attribution - NonCommercial - NoDerivatives| 4.0 


\section{Le sanctuaire protohistorique de la Fontaine à Nimes, à la lumière des découvertes récentes.}

L. SAUVAGE, chercheur associé à I'UPR $290 \mathrm{du}$ CNRS

C'est autour de la source pérenne de la Fontaine, à Nimes, que se fixe un premier habitat groupé à la fin du VIe s. av. n. è. Si l'on reconnait dans cette source un lieu de culte protohistorique lié à l'eau depuis la découverte au XVIIle s. d'inscriptions votives en gallogrec à ses abords, on ne connait paradoxalement que très peu de choses sur ce sanctuaire indigène qui cèdera la place à un sanctuaire du culte impérial, interprété récemment comme l'Augusteum de la colonie nimoise. La mise au jour, à l'occasion des fouilles de la Z.A.C. Villa Roma (M. Piskorz dir.) situées à proximité immédiate de la source de la Fontaine, de documents nouveaux d'un intérêt exceptionnel, permet, avec l'aide de la documentation préexistante, de préciser la question de l'existence et de la nature d'un sanctuaire protohistorique autour de la Fontaine de Nimes.

Le radical celtique "nem" à l'origine du nom antique de Nimes évoque un espace sacré, qui, par extension, s'est rapporté à une localité, et enfin à la divinité éponyme Nemausus la symbolisant à l'époque romaine. Il est alors permis de penser que le sanctuaire des origines devait correspondre à un lieu consacré, un sanctuaire topique, n'ayant pas ou peu reçu d'aménagements monumentaux. jusqu'à une date avancée de la Protohistoire.

Si la présence sur le numéraire nimois d'époque républicaine de symboles liés à la source et l'existence à la même époque d'exvoto monumentaux reflètent la vitalité et l'importance du sanctuaire des eaux, la découverte récente, immédiatement au sud du "temple de Diane", d'un monument à portique et d'autres vestiges connexes, livre des éléments déterminants en vue d'une restitution de l'aspect du sanctuaire d'époque républicaine. En effet, ils apportent la preuve tangible d'un puissant réaménagement de l'environnement de la source, antérieurement à l'époque augustéenne. Ainsi, un monument public de grandes dimensions et de très belle facture, est bàti au tout début du Ier s. av. J.-C. au sein d'un paysage aménagé en terrasses. Cette phase de construction marque une rupture fondamentale avec l'esprit et l'aspect de l'aire sacrée antérieure. L'environnement naturel du lieu de culte originel est désormais restructuré et reçoit un traitement architectural d'inspiration gréco-italique, où sont intégrés monuments de tradition indigène -le monument à portique-, ou appartenant au répertoire héllénistique (ex-voto monumentaux à inscription et statue).

La construction de l'Augusteum à la fin du ler s. av. n. è., selon les mêmes axes urbanistiques que le monument à portique, à une époque où celui-ci a été démantelé et a cédé la place à une terrasse monumentale, implique l'existence d'autres édifices appartenant à un complexe antérieur à l'époque augustéenne. En reprenant les directions architecturales de ce dernier, le sanctuaire romain s'approprie alors symboliquement l'espace cultuel indigène, qui présente ainsi, par ses caractères ei son évolution, de très nombreuses similitudes avec le sanctuaire de Glanum.

Bibliographie :

On se reportera à l'étude détaillée des découvertes présentées ici dans le volume à paraître (mars 1993) des Documents d'Archéologie Méridionale : contributions de M. Piskorz et coll., A. Barbet, J.-C. Bessac, M. Lejeune, L. Sauvage. 